trivia and tomato aroma: Biochemistry and possible mechanisms for control of important aroma components. HortScience 35(6):1013-1022.

Bruhn, C.M., N. Feldman, C. Garlitz, J. Harwood, E. Ivans, M. Marshall, A. Riley, D. Thurber, and E. Williamson. 1991. Consumer perceptions of quality: Apricots, cantaloupes, peaches, pears, strawberries, and tomatoes. J. Food Qual. 14:187-195.

Buttery, R.G. 1993. Quantitative and sensory aspects of flavor of tomato and other vegetables and fruits, p. 259-286. In: T.E. Acree and R. Teranishi (eds.). Flavor science: Sensible principles and techniques. Amer. Chem. Soc., Washington, D.C.

Buttery, R.G. and L.C. Ling. 1993a. Enzymatic production of volatiles in tomatoes, p. 137-146. In: P. Schreier and P. Winterhalter (eds.). Flavor precursors. Allured Publ., Wheaton, Ill.

Buttery, R.G. and L.C. Ling. 1993b. Volatiles of tomato fruit and plant parts: Relationship and biogenesis, p. 23-34. In: R. Teranishi, R. Buttery, and H. Sugisawa (eds.). Bioactive volatile compounds from plants. ACS Books, Washington, D.C.

Davies, J.N. and G.E. Hobson. 1981. The constituents of tomato fruit-The influence of environment, nutrition and genotype. CRC Crit. Rev. Food Sci. Nutr. 15:205-280.

Emery, G.C. and H.M. Munger. 1970. Effects of inherited differences in growth habit on fruit size and soluble solids in tomato. J. Amer. Soc. Hort. Sci. 95(4):410-412.

Eshed, Y. and D. Zamir. 1995. An introgression line population of Lycopersicon pennellii in the cultivated tomato enables the identification and fine mapping of yield-associated QTL. Genetics 141:1147-1162.

Fridman, E., T. Pleban, and D. Zamir. 2000. A recombination hotspot delimits a wild-species quantitative trait locus for tomato sugar content to $484 \mathrm{bp}$ within an invertase gene. Proc. Natl. Acad. Sci. USA 97:4718-4723.

Ibarbia, E.A. and V.N. Lambeth. 1969. Inheritance of soluble solids in a large/ small-fruited tomato cross. J. Amer. Soc. Hort. Sci. 94(5):496-498.

Jones, R.A. and S.J. Scott. 1984. Genetic potential to improve tomato flavor in commercial $F_{1}$ hybrids. J. Amer. Soc. Hort. Sci. 109(3):318-321.

Kader, A.A., M.A. Stevens, M. Albright-Holton, L.L. Morris, and M. Algaze. 1977. Effect of fruit ripeness when picked on flavor and composition in fresh market tomatoes. J. Amer. Soc. Hort. Sci. 102(6):724-731.

Kavanaugh, E.E. and W.B. McGlasson. 1983. Determination of sensory quality in fresh market tomatoes. CSIRO Fd. Res. Q. 73:81-89.

Kopeliovitch, E., Y. Mizrahi, H.D. Rabinowitch, and N. Kedar. 1982. Effect of the fruit-ripening mutant genes rin and nor on the flavor of tomato fruit. J. Amer. Soc. Hort. Sci. 107(3):361-364.

Kopeliovitch, E., H.D. Rabinowitch, Y. Mizrahi, and N. Kedar. 1979. The potential of ripening mutants for extending the storage life of the tomato fruit. Euphytica 28:99-104.

Levin, I., N. Gilboa, E. Yeselson, S. Shen, and A.A. Schaffer. 2000. Fgr, a major locus that modulates the fructose to glucose ratio in mature tomato fruits. Theor. Appl. Genet. 100:256-262.

Lower, R.L. and A.E. Thompson. 1967. Inheritance of acidity and solids content of small-fruited tomatoes. Proc. Amer. Soc. Hort. Sci. 91:486-494.

Malundo, T.M.M., R.L. Shewfelt, and J.W. Scott. 1995. Flavor quality of fresh tomato (Lycopersicon esculentum Mill.) as affected by sugar and acid levels. Postharv. Biol. Technol. 6:103-110.

Speirs, J., E. Lee, K. Holt, K. Yong-duk, N.S. Scott, B. Loveys, and W. Schuch. 1998. Genetic manipulation of alcohol dehydrogenase levels in ripening tomato fruit affects the balance of some flavor aldehydes and alcohols. Plant Physiol. 117:1047-1058.

Stevens, M.A. 1972. Citrate and malate concentrations in tomato fruits: Genetic control and maturational effects. J. Amer. Soc. Hort. Sci. 97(5):655685.

Stevens, M.A., Adel A. Kader, and Marjorie Albright. 1979. Potential for increasing tomato flavor via increased sugar and acid content. J. Amer. Soc. Hort. Sci. 104(1):40-42.

Stevens, M. Allen, Adel A. Kader, M. Albright-Holton, and M. Algaze. 1977. Genotypic variation for flavor and composition in fresh market tomatoes. J. Amer. Soc. Hort. Sci. 102:680-689.

Stevens, M.A. and M.A. Long. 1971. Inheritance of malate in tomatoes. J. Amer. Soc. Hort. Sci. 96:120-122.

Stevens, M.A. and J. Rudich. 1978. Genetic potential for overcoming physiological limitations of adaptability, yield, and quality in the tomato. HortScience 13(6):673-678.

Stoner, A.E. and A.E. Thompson. 1966. A diallel analysis of solids in tomatoes. Euphytica 15:372-377.

Walkof, C. and R.B. Hyde. 1963. Inheritance of acidity in tomatoes. Can. J. Plant Sci. 48:528-533.

Watada, A.E. and B.B. Aulenbach. 1979. Chemical and sensory qualities of fresh market tomatoes. J. Food Sci. 44:1013-1016.

West, J.R. 2000. Segmentation of tomato consumers by preferences in flavor acceptability. MS Thesis, Univ. of Georgia. 53 p.

\title{
Opportunities in Using Biotechnology to Maintain Postharvest Quality and Safety of Fresh Produce
}

\author{
Adel A. Kader \\ Department of Pomology, University of California, One Shields Avenue, Davis, CA 95616
}

The primary goals of research on postharvest biology and technology of fresh produce are to reduce losses in quantity and quality between harvest and consumption. The strategies for attaining these goals include selection of genotypes with good sensory quality when harvested at optimum maturity, use of an integrated crop management system that maximizes yield without sacrificing quality, and use of optimum postharvest handling procedures to maintain the quality and safety of the produce. Providing consumers with fruits and vegetables that taste good can greatly encourage their consumption of the recommended minimum of five servings per day for better health. The most useful technological changes in the production, harvesting, and postharvest handling systems for horticultural crops have resulted from interdisciplinary research and development approaches and this is likely to continue to be true in the future. Thus, biotechnology is a tool that can be utilized in an interdisciplinary approach, to address some of the concerns about quality attributes and the biological causes of

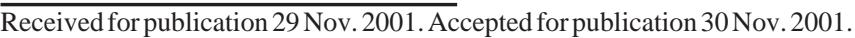

deterioration of harvested produce. In this brief overview, I will provide some examples of the opportunities and limitations in using biotechnology to maintain postharvest quality and safety of fresh produce.

Composition and appearance quality. Color is a very important appearance quality factor that is related to biosynthesis and degradation of pigments, including chlorophylls, carotenoids, and flavonoids. Biotechnology can be used to improve color uniformity and intensity and to minimize undesirable colors, such as browning. Tissue browning is dependent upon the concentration of phenolic compounds, the activity of polyphenol oxidase (PPO), and the concentration of antioxidants. These factors can be manipulated to produce genotypes with low browning potential, which is a very useful trait in many commodities when marketed intact or as fresh-cut products. The feasibility of such approach has been shown in potatoes with blocked PPO synthesis.

Composition and textural quality. Genetic manipulations to reduce the rate of lignification (toughening) of vegetables, such as asparagus and green beans, can be very useful in maintaining their textural quality. Another use for biotechnology is to reduce the rate of fruit 
softening to maintain their firmness and minimize physical damage throughout the postharvest handling system. This can be achieved by altering cell wall metabolism in all fruits and/or ethylene biosynthesis and action in climacteric fruits, as has been demonstrated in tomatoes.

Composition and flavor quality. Flavor quality factors include sweetness (kinds and quantity of sugars), sourness or acidity (kinds and quantity of acids), astringency (phenolic compounds), and aroma or odor (volatile compounds). The relative importance of each of these factors and their interactions depends upon the commodity. The greatest need is to produce new fruit genotypes with better flavor, which means high sugars (or greater proportion of fructose and/or sucrose than glucose) and moderate to high acids (with balance between them), low phenolics, and enough of the organoleptically important volatiles for good aroma. Since flavor quality involves perception of the tastes and aromas of many compounds, it is much more challenging to manipulate than other quality factors. This has been true for plant breeders in the past and it will continue to be so with biotechnology approaches. This may be the reason that improvement of flavor quality has received much less attention from biotechnologists so far than textural quality of fruits.

Composition and nutritional quality. Plant breeders have been successful in selecting genotypes with much higher contents of ascorbic acid (vitamin C) in guava and tomatoes, beta carotene (provitamin A) in carrots and tomatoes, and flavonoids in berries. Biotechnology approaches can be utilized to improve the content of vitamins, minerals, dietary fiber, and phytonutrients in fruits and vegetables, especially those with high per capita consumption rates. Phytonutrients that can lower the risk of heart disease, cancer, and other diseases include carotenoids, flavonoids (anthocyanins, phenolic acids, polyphenols), isoflavones, phytosterols, and organosulfur compounds. The antioxidant capacity of fruits, nuts, and vegetables is related to their contents of anthocyanins, phenolic compounds, carotenoids, ascorbic acid, and vitamin E. Large genotypic variations in total antioxidant capacity have been shown in many commodities, indicating the potential for further improvements using biotechnology. Another opportunity for use of biotechnology is to alter the fatty acids composition of some nuts to reduce their content of saturated fatty acids.

Rates of respiration and ethylene production. In many commodities we find an association between their postharvest life (rate of deterioration) and their rates of respiration and ethylene production. Selecting genotypes with lower rates of respiration and ethylene production is likely to result in lower rates of deterioration and longer postharvest life potential. However, in cases when ethylene production is largely inhibited in fruits, their volatile production is also inhibited, which has a negative impact on their aroma quality. The challenge is to separate the effects of genetic manipulation on ethylene biosynthesis from those on biosynthesis of esters and other desirable aroma volatiles.

Susceptibility to physiological disorders. Many physiological disorders have been identified and associated with exposure to undesirable temperatures, with low calcium levels, with $\mathrm{O}_{2}, \mathrm{CO}_{2}$, and/or $\mathrm{C}_{2} \mathrm{H}_{4}$ concentrations beyond those tolerated by the fruit, or with other factors. However, the physiological and biochemical basis of most of these disorders remains largely unknown.

Thus, physiologists and biochemists need to identify the specific targets for biotechnological manipulation before biotechnology can be used to address these problems. Genotypic differences in susceptibility to chilling injury have been shown in most chilling-sensitive commodities. Thus, it should be possible to use biotechnology to produce cultivars with lower chilling sensitivity to allow their handling at lower temperatures to extend their postharvest life. This is especially critical for tropical and subtropical commodities and for some temperate fruits that have low-temperature disorders, such as internal breakdown of stone fruits and scald of apples and pears. Another opportunity for biotechnology is to produce cultivars of nonfruit vegetables, such as broccoli and lettuce and flowers that are less susceptible to ethylene action. However, it is advisable to evaluate the feasibility and cost/benefit analysis of this approach in comparison with currently available treatments with 1-methylcyclopropene to inhibit ethylene action.

Susceptibility to pathological breakdown. One of the most common and obvious symptoms of deterioration results from the activity of fungi. Attack by most organisms follows physical injury or physiological breakdown of the commodity. In a few cases, pathogens can infect apparently healthy tissues and become the primary cause of deterioration. In general, harvested fruits exhibit considerable resistance to potential pathogens during most of their postharvest life. The onset of ripening in fruits results in their becoming susceptible to infection by pathogens. There is an association between phenolic content in many commodities and their susceptibility to decay-causing pathogens. However, the challenge to biotechnological approaches is to maintain a balance between the desirable concentrations of phenolic compounds for resistance to pathogens and the undesirable levels in terms of astringency and/or browning potential. Another approach is to introduce polygalacturonase inhibitors and/or to increase the level of endogenous antifungal compounds without negative effects on quality and safety of the commodity.

Safety considerations. Minimizing chemical and microbial contamination during production, harvesting, and postharvest handling of fruits and vegetables is essential to assuring their safety to the consumer. Research and development efforts must continue to define optimum procedures for avoiding contamination with mycotoxins, heavy metals, and microorganisms during handling of fresh fruits and vegetables and their products. It may be possible to use biotechnology to alter the morphological structure of the surface of some commodities to minimize the areas in which human pathogens can be protected from washing and disinfection treatments.

Conclusions. It is clear that there are numerous opportunities in using biotechnology to maintain postharvest quality and safety of fresh produce. Thus, priorities for each commodity should be established on the basis of the relative importance of its postharvest deterioration causes and what is needed to encourage increased consumption. Overall, priority should be given to the following three goals:

- To attain and maintain good flavor and nutritional quality to meet consumer demands and encourage greater consumption of fresh fruits and vegetables.

- To introduce resistance to physiological disorders and/or decay-causing pathogens to reduce use of chemicals.

- To modify surface structure and/or composition of some commodities to reduce their microbial contamination potential.

The keys to success in maintaining quality and safety of biotechnologically produced genotypes of flowers, fruits, and vegetables are the same as those currently recommended, i.e., optimum maturity at harvest, careful and expedited handling, maintenance of optimum ranges of temperature and relative humidity, and minimizing chemical and microbiological contamination throughout the postharvest handling system. It is possible that new genotypes will void the need for some supplemental treatments to the commodity or its environment, but it is not likely that the need for paying attention to all the details of the above-mentioned keys to successful handling will be reduced. 